\title{
Culturally Sensitive Website Elements and Features: A Cross-National Comparison of Websites from Selected Countries
}

\author{
Radim Cermak 1 (D)
}

\begin{abstract}
The goal of this case study is to compare websites from 9 different countries-Austria, Chile, China, Japan, Latvia, Nigeria, Saudi Arabia, the US and the Czech Republic-and, based on this comparison, to provide the missing linking of website elements with cultural dimensions for better cultural adaptation of web content. Hofstede's cultural dimensions were used for the selection of countries for this study. To examine the influence of culture on websites, countries with extreme values of cultural dimensions were selected. An important benefit is that this study takes into account all of Hofstede's cultural dimensions, including the latest one (indulgence vs restraint). For each country 50 websites were selected from areas that most closely reflect the culture of the country. The main focus was on the selection of an appropriate representative sample of websites for each state. A total of 450 pages was analyzed. For each website, 42 web elements determined as the most important were monitored. Moreover, the presence of various types of social networks and five general characteristics were monitored. The findings show that culture influences website design. The results of this study reveal a connection between website elements and Hofstede's cultural dimensions. For example, headlines are important for countries with a high value of individualism, uncertainty avoidance, and a low value of power distance and indulgence. Newsletters are associated with a high value of indulgence and a low value of long-term orientation and search option with a high value of power distance. Overall, about 20 culturally sensitive website elements were identified. The study also provides a comprehensive overview of website characteristics for each of the selected countries. For UX designers, web localization specialists, academicians, and web developers, this study provides an original view into culturally sensitive website elements and features.
\end{abstract}

Keywords: Culture, E-commerce, Hofstede's cultural dimensions, Human-computer interaction, Webdesign, Website.

\section{Introduction}

With the spread of the Internet, the importance of websites for companies but also for individuals and public and state institutions is increasing. Websites are now one of the most important information channels. Currently, the website is for many people the first place to visit when they look for information about a product or a company. The importance of this media can be demonstrated also by the numbers. The amount of money invested in Internet advertising grows every year. Sales in the e-commerce area grow every year as well.

\footnotetext{
${ }^{1}$ Department of Systems Analysis, Faculty of Informatics and Statistics, Prague University of Economics and Business, W. Churchill Sq. 1938/4, 13067 Prague, Czech Republic

$\bowtie$ radim.cermak@vse.cz
} 
Many companies now operate outside of their home country. They are often part of a market with a different culture. This results in the need to adapt communication in a way that will be understood by users from a different culture. Companies should avoid any misunderstandings. It means that if a company wants to communicate adequately and effectively with people from different cultures, it is necessary to localize the company's websites.

When discussing localization, we must start from the premise that the website is a culturally sensitive medium. Many studies have already investigated the question of whether culture affects websites. Among the first attempts to determine whether a website is a culturally sensitive medium, and how this cultural sensitivity is shown, are following studies (Marcus \& Gould, 2000; Marcus, 2003; Simon, 2001). Many studies have already tried to find the differences between websites from different countries and formulate general conclusions (Wurtz, 2005; Cyr \& Trevor-Smith, 2004; Singh, Baack 2004). Other studies have examined the impact of culture on users' acceptance and ease of use (Li et al., 2009; Cyr, 2008; Daryanto et al., 2013). Yet other studies have tried to create a framework that would connect web elements and features with cultural properties (Singh \& Matsuo, 2002; Wurtz, 2005; Karacay-Aydin et al., 2009). The study (Shneor, 2012) offers information about the influences of the decision to create a localized website in a foreign country. The study (Reinecke \& Bernstein, 2013) tested an adaptive user interface on users from Rwanda, Switzerland, Thailand, and on multicultural users. The study (Singh et al., 2013) offers an insight into the current state of B2B websites based on content analysis of websites from the US and South Korea. The result is the proposal of a comprehensive framework for measuring the degree of localization of websites in a B2B environment.

The study (Calabrese et al., 2014) shows a constant topicality of the investigated issue. The result of the study, based on comprehensive literature research, content analysis, and contingency analysis, is that the website is not a culturally neutral medium at all, and the localization of the website is one of the key factors of business success. The cultural sensitivity of websites is also shown also in the study (Nordhoff et al., 2018), where authors compared websites from 44 countries. They found that the design of websites with a global reach is more homogenized compared to local websites. According to (Radziszewska, 2019), culture dimensions (defined by Hofstede and Hall) influence e-commerce website design because local cultures influence consumer online behavior and expected B2C website quality characteristics. All mentioned studies clearly show the cultural sensitivity of websites.

Perhaps the best evidence of the cultural sensitivity of websites is offered by the study (Vyncke \& Brengman, 2010). This study provides an overview of an entire decade of website cultural sensitivity research. The result of this study confirms the hypothesis that websites aligned with a given culture are more effective than websites that ignore cultural values in areas of usefulness, ease of use, generating positive attitude, positive intentions, and overall effectiveness. This study confirms the importance of research focusing on the creation of websites for various cultural areas.

As can be seen from the above-mentioned studies, by localization is not meant just a pure translation. For a comprehensive localization of websites, it is necessary to adjust also website content and design. Relatively many studies have already dealt with the question of how to perform localization of content and design. These studies were devoted to determining culturally sensitive properties and their subsequent linking with cultural dimensions.

Cultural properties are in the literature mostly represented by Hofstede's cultural dimensions (Singh \& Matsuo, 2002; Sachau \& Hutchinson, 2012; Calabrese et al., 2014) or Hall's cultural dimensions, or more precisely by a combination of these cultural dimensions, see e.g. 
(Singh et al., 2003; Karacay-Aydin et al., 2009; Yalcin et al., 2011). Hofstede's cultural dimensions are in this area the most frequently used way to "describe" cultural properties. It is important to mention that there are also critics of this concept. One of the most serious criticisms can be found in the study (McSweeney, 2002a). According to it, Hofstede's cultural dimensions are based on fundamentally flawed assumptions which make the whole concept of cultural dimensions invalid. The main drawback concerns the use of average IBM responses that cannot reflect 'the' national average and questions whether he was able to adequately depict national cultures and national cultural differences. The study (Imm et al., 2007) compares Hofstede's and Schwartz's framework of values and points out that Hofstede's cultural dimensions may not properly evaluate cultural view on certain sectors. Ailon (2008) stressed that Hofstede's work simplifies the reality and is Western-oriented with a tendency to separate the West and "the Rest".

Another criticism focuses in particular on methodological weaknesses. This is related to the average values that are used to characterize different nations. The critics say that each national culture is itself quite differentiated (Průcha, 2007, pp. 183, 184). This opinion can be supported for example by the study (Pratap \& Kumar, 2019). The authors have proven cultural differences regarding website elements within selected cultural zones in India. The criticism often concerns also the failure of dimensions to consider cultural changes over time (Kirkman et al., 2006). Hofstede himself summarizes the most common criticism in five points in his study (Hofstede, 2002). He also adds his defence, which indicates the adequacy of the concept. This article was questioned by McSweeney (2002b). He points out that Hofstede's defence is characterized by evasion and points out inconsistencies in Hofstede's reply. McSweeney's reply is important because it stresses the importance of the fact that culture is a really complex concept with more levels. It also reminds us that the model of national culture could be problematic. In case it's considered as a necessary simplification of reality, this concept could be helpful and has its defenders. The adequacy of the use of Hofstede's cultural dimensions is proven also by (Steenkamp, 2001). He identified this framework as rigorous and comprehensive and therefore very suitable for the development of a theory in the field of international marketing. The framework has also been extensively tested in the context of literature devoted to advertising and marketing, see e.g. (Albers-Miller \& Gelb, 1996; Milner \& Collins, 2000; Zandpour et al., 1994). The use of this framework was also later extended to the study of web communication, see (Singh \& Matsuo, 2004; Singh et al., 2005 a, b). The advantages of this framework are also confirmed by (Tang \& Koveos, 2008), stating that Hofstede's dimensions have a much greater impact than any other cultural framework and according to (Kirkman et al., 2006), Hofstede's framework is the best mainly due to the clarity and simplicity of use. The correctness of cultural dimensions was validated also within the field of neuroscience. Studies (Delude, 2008; Chavanne, 2007) confirmed cross-national differences related to individualism and collectivism ${ }^{1}$.

It is important that none of the studies that investigated the linking of website features with cultural dimensions take into account the complete set of Hofstede's cultural dimensions. For example, the study (Ahmed et al., 2009) considers the cultural dimension of power distance and Hall's dimension of context. The study (Sachau \& Hutchinson, 2012) considers power

\footnotetext{
${ }^{1}$ Culture is a complex concept that covers many things related to our way of living. It has many layers and cannot be classified easily. However, for scientific purposes, we have to handle it somehow and the best option is currently still Hofstede's cultural framework. Even if itis just a necessary simplification of reality. This case study uses the same approach as many other studies that investigated cultural differences. It is not the goal of this study to argue whether Hofstede's cultural framework is worth using or not. It is also important to explicitly say that when "culture" is mentioned in this study, it is always meant as national culture. Using this nomenclature is in line with the use of cultural dimensions for the characterization of national culture and cultural differences among countries.
} 
distance, context, and uncertainty avoidance; (Wurtz, 2005) considers power distance and context; (Karacay-Aydin et al., 2009) consider uncertainty avoidance, individualism and collectivism, masculinity and femininity and context; (Singh et al., 2005b) focus on individualism and collectivism, uncertainty avoidance, power distance, masculinity and femininity and context.

Furthermore, none of the studies offers a link of specific website elements with cultural dimensions - this is identified as a major knowledge gap within the investigated literature. The result is usually just a general statement or a common description of features. An example might be the feature Company hierarchy information corresponding to a high value of power distance. This feature is described as follows: Information about the ranks of company personnel, information about an organizational chart, and information about country managers (Singh et al., 2005b). The feature "We" approach corresponding to a high value of collectivism is reflected in the use of words such as we, ours, together (KaraçayAydin et al., 2010); the feature Web visitor support corresponding to a high value of uncertainty avoidance that is described as help section, link to how to use the Web site, information on how to use a computer, and / or a Frequently Asked Questions (FAQs) section (Sachau \& Hutchinson, 2012). A final example can be the general statement provide strong support or with the help of wizards corresponding to a high value of power distance (Reinecke \& Bernstein, 2011).

The main goal of this case study is to focus on the missing linking of website elements with cultural dimensions for better cultural adaptation of web content. An additional goal is to examine websites' general features and provide a comprehensive overview of website characteristics for each of the selected countries. Another benefit of this study is that it considers all Hofstede's cultural dimensions, including the newest dimension called indulgence vs restraint. Culturally sensitive website elements are identified, based on the content analysis of websites from 9 culturally different countries of the world. The mentioned elements were linked with Hofstede's cultural dimensions and as such created a set of culturally influenced website elements. Selected countries are presented in the Methodology section. The findings should be useful mainly for UX designers and website localization specialists. For example, when a UX designer is creating a design for the website of a company that sells its products in Japan and in the US, he or she can create a localized design that will be intuitive and easy to use for users from both countries.

\section{Methodology}

A case study approach was used to investigate culture-specific website elements. Case study is a relevant research method, confirmed by literature (Yin, 2014). A case study should cover the following steps: determine the research question, choose the research design, prepare to collect the data, collect the data, analyse the data and share the data.

The first step of case study is defining the research question. In our case, the researched question was defined as follows: "Are there any differences in the web design approach and used website elements between the selected countries?" The answer to this question should help us to achieve our primary goal - to determine the missing linking of website elements with cultural dimensions for better cultural adaptation of web content.

The research design is based on the content analysis of websites from different countries, comprehensive literature research and a final synthesis of results. The preparation phase was mainly focused on considering how the data was to be gathered, which countries should be 
included in the selection and which websites and website elements should be considered for data gathering.

The collection of the data was executed using content analysis according to the approach described in detail below in this chapter. Once the data was gathered, it was analysed and compared with the results from literature research. Case study results should be shared via the publication in scientific journals.

It is important to say that as this study used a qualitative research method, the results are not generalizable, though they provide an insight into culturally sensitive web design. The following paragraphs describe in detail the research design that was used.

Content analysis was used for comparison of websites from different countries. The author analysed the content of the website in terms of preselected web elements. This is a commonly used procedure applied for example in studies (Hashim et al., 2007; Adam et al., 2014; Karacay-Aydin et al., 2009; Ahmed et al., 2009; Singh et al., 2013). As a result of content analysis, a dataset was created of website elements displayed on websites from different countries. This dataset was then analysed more deeply and based on that, the final results were stated.

The subject of the content analysis were websites from the selected countries. In total 50 , websites were selected from each country and 42 web elements were monitored on each website. Moreover, the use of social networks and the general properties were monitored as well. These included: information density, overall colour, saturation/brilliance, text to graphics ratio, and overall complexity of web design (evaluation is presented below).

The values of Hofstede's cultural dimensions were extremely important for the choice of countries. Hofstede's cultural dimensions are commonly used as the master key for distinguishing countries in terms of their cultural differences. Despite the already mentioned criticism of the use of cultural dimensions, this is the most appropriate way. It is the most frequently used method in scientific literature. As an example, the following studies could be mentioned: (Ahmed et al., 2009; Vyncke \& Brengman, 2010; Yalcin et al., 2011; Li et al., 2009; Karacay-Aydin et al., 2009). The difference between cultures was the main factor for the selection of countries. For a better comparison, countries with the most extreme values of cultural dimensions are needed.

The following countries were chosen for the comparison: the Czech Republic (Czechia), the United States (US), China, Chile, Saudi Arabia, Nigeria, Latvia, Japan, and Austria. Within this selection, some countries represent the extreme values of Hofstede's cultural dimensions, which is necessary for the purposes of this work. Some selected countries are also countries that are very often used for cultural comparison by other authors (US and China (Li et al., 2009; Singh et al., 2003), US and Japan (Singh \& Matsuo, 2002), US, China and Japan (Singh et al., 2005b)). An exception is Czechia, which was chosen because it is the author's home country and has not yet been investigated from this perspective. Table 1 shows all the countries and their values of Hofstede's cultural dimensions.

To determine the dependence of the web elements on the cultural dimensions, it was necessary to define the dominant cultural dimensions. For each country, one primary cultural dimension was established. A secondary and a tertiary dimension was also set to enable a more complex view and generalization. This division will subsequently be used for the analysis of web elements and their linking to the cultural characteristics of the selected countries. 


\begin{tabular}{|l|c|c|c|c|c|c|}
\hline & $\begin{array}{c}\text { Power } \\
\text { distance } \\
\text { (PD) }\end{array}$ & $\begin{array}{c}\text { Individualism vs } \\
\text { collectivism (IND) }\end{array}$ & $\begin{array}{c}\text { Masculinity vs } \\
\text { femininity } \\
\text { (MAS) }\end{array}$ & $\begin{array}{c}\text { Uncertainty } \\
\text { avoidance (UA) }\end{array}$ & $\begin{array}{c}\text { Long term } \\
\text { orientation } \\
\text { (LTO) }\end{array}$ & $\begin{array}{c}\text { Indulgence vs } \\
\text { restraint } \\
\text { (IVR) }\end{array}$ \\
\hline Czechia & 57 & 58 & 57 & 74 & 70 & 29 \\
\hline US & 40 & 91 & 62 & 46 & 26 & 68 \\
\hline China & 80 & 20 & 66 & 30 & 87 & 24 \\
\hline Chile & 63 & 23 & 28 & 86 & 31 & 68 \\
\hline $\begin{array}{l}\text { Saudi } \\
\text { Arabia }\end{array}$ & 95 & 25 & 60 & 80 & 36 & 52 \\
\hline Japan & 54 & 46 & 95 & 92 & 88 & 42 \\
\hline Nigeria & 80 & 30 & 60 & 55 & 13 & 84 \\
\hline Latvia & 44 & 70 & 9 & 63 & 69 & 13 \\
\hline Austria & 11 & 55 & 79 & 70 & 60 & 63 \\
\hline
\end{tabular}

Tab. 1. Values of Hofstede's cultural dimensions. The range of values is from 0 to 100 . Values close to 0 or 100 are considered extreme values and as such have the biggest influence on the national culture. Source: (Hofstede, 2015)

The primary cultural dimension means the country's dominant dimension. It is the cultural dimension that has the most extreme value in this country (minimum or maximum). The secondary cultural dimension is also represented by an extreme value, but not as extreme as in the case of the primary dimension. It must also fulfil the condition that the difference compared to average is at least 30 points $^{2}$. The same applies in the case of tertiary dimensions. A minimal difference compared to the average is at least 20 points $^{3}$. This division enables mapping the differences within websites to the cultural dimensions with the possibility of further generalization of the results.

Table 2 shows the choice of primary $(\mathrm{P})$, secondary $(\mathrm{S})$, and tertiary $(\mathrm{T})$ dimensions for each state. The primary dimension is displayed in bold. For each dimension, information is also given about whether the level is high or low, i.e. whether it approaches the minimum or the maximum extreme. An exception is the Czech Republic, which from the perspective of the surveyed countries acquires rather average values ${ }^{4}$ because only tertiary cultural dimensions were selected in this case.

\begin{tabular}{|c|c|c|c|c|c|c|}
\hline & $\begin{array}{c}\text { Power } \\
\text { distance (PD) }\end{array}$ & $\begin{array}{l}\text { Individualism vs } \\
\text { collectivism (IND) }\end{array}$ & $\begin{array}{c}\text { Masculinity vs } \\
\text { femininity } \\
\text { (MAS) }\end{array}$ & $\begin{array}{c}\text { Uncertainty } \\
\text { avoidance (UA) }\end{array}$ & $\begin{array}{c}\begin{array}{c}\text { Long term } \\
\text { orientation } \\
\text { (LTO) }\end{array} \\
\end{array}$ & $\begin{array}{l}\text { Indulgence vs } \\
\text { restraint (IVR) }\end{array}$ \\
\hline Czechia & & & & High $(\mathrm{T})$ & High (T) & Low (T) \\
\hline US & & High (P) & & & Low $(\mathrm{T})$ & \\
\hline China & High (S) & Low $(\mathrm{S})$ & & Low $(\mathrm{T})$ & High (P) & Low $(\mathrm{T})$ \\
\hline Chile & & Low $(\mathrm{T})$ & Low $(\mathrm{T})$ & High $(\mathbf{P})$ & & \\
\hline S.A. & High (P) & Low $(\mathrm{T})$ & & High (S) & & \\
\hline Japan & & & High $(\mathbf{P})$ & $\operatorname{High}(\mathrm{S})$ & $\operatorname{High}(\mathrm{S})$ & \\
\hline Nigeria & $\operatorname{High}(\mathrm{S})$ & Low $(\mathrm{T})$ & & & Low $(\mathbf{P})$ & High (S) \\
\hline
\end{tabular}

${ }^{2}$ The values of cultural dimensions are between 0 and 100 .

${ }^{3}$ Tertiary dimensions don't show such extreme values. There is therefore higher probability of influence of other cultural dimensions. This assumption will be taken into account in the analysis. Even though, it is a cultural dimension which is important for the country and therefore must be considered in the analysis.

${ }^{4}$ The Czech Republic does not have any significant extreme. However, it has quite average values of cultural dimensions and thus it can be used as an average country, which brings a benefit to the overall comparison of the countries. There are also tertiary dimensions that will be used. 


\begin{tabular}{|l|c|c|c|c|c|c|}
\hline & $\begin{array}{c}\text { Power } \\
\text { distance (PD) }\end{array}$ & $\begin{array}{c}\text { Individualism vs } \\
\text { collectivism (IND) }\end{array}$ & $\begin{array}{c}\text { Masculinity vs } \\
\text { femininity } \\
\text { (MAS) }\end{array}$ & $\begin{array}{c}\text { Uncertainty } \\
\text { avoidance (UA) }\end{array}$ & $\begin{array}{c}\text { Long term } \\
\text { orientation } \\
\text { (LTO) }\end{array}$ & $\begin{array}{c}\text { Indulgence vs } \\
\text { restraint (IVR) }\end{array}$ \\
\hline Latvia & & High (T) & Low (P) & & & Low (S) \\
\hline Austria & Low (P) & & High (T) & Low (T) & & \\
\hline
\end{tabular}

Tab. 2. Assessment of each country from the cultural dimensions perspective. Cultural dimensions with extreme values are considered as primary $(P)$, high or low values are taken as secondary $(S)$ and tertiary $(T)$ cultural dimensions. Average values are not considered. This assessment helps to determine the influence of cultural dimensions on selected countries. Source: Author.

Websites were selected to reflect the culture of the country as much as possible. The aim was also to create a representative sample - to have websites from different sectors and targeting different age groups and audiences.

Therefore, the first step was to identify the sectors that would be used for analysis. These sectors should vary and be mainly connected with the local clientele. That should force website owners and developers to create a website that is designed especially for local users. This should mean that these websites will maximally reflect the culture of the country.

The following sectors were selected: automotive (mainly focusing on car repair shops, service stations, car showrooms, tire services or services associated with the use of motor vehicles), food (focus on restaurants and other forms of eating), accommodation (focus on local forms of accommodation such as guesthouses, hostels, apartments, etc.), furniture (especially custom-made furniture or furniture showrooms) and website creation. To search for these websites, the following primary keywords/phrases were used: car repair shop, restaurant, guest house, custom furniture, website creation.

Google was used as the main search engine (specifically Google advanced search). It enables setting the country and the language of websites. Logically, the appropriate keyword was always used, e.g. for Czech websites the keyword autoservis (car repair shop) was used and the advanced search was then set to search sites in the Czech language and the region of Czech Republic. The exception was the search for Chinese and Japanese sites. Local search engines, which were used for these countries, are more popular in these countries and thus should provide better results. In the case of China, the search engine at baidu.com was used, and in the case of Japan it was the search engine at izito.jp. Czech websites were searched first. Keywords were then translated into English and used to track down websites in the US. English translations were then used for further translation into other languages. Google translator was used to translate the keywords. The searched keywords were always translated into the appropriate language before they were used for searching. In some cases, it was still necessary to specify the results more clearly. For such cases, the country's name was added to the keyword. When even this did not help, it was necessary to add an even more specific keyword - a city from the selected country (if such specification was used, it was always the country's capital). These restrictions were applied mainly because in many cases the search results for the keyword offered a jumble of aggregators and graders. Websites of specific companies then could not be traced. This limitation concerns mainly China and to some extent also Saudi Arabia and Japan.

The top 10 entries were selected this way. One rule was applied to the selection of websites: if a website has another language version, this version must not be different from the major version in terms of web design (i.e. web graphics, web layout elements, content and site structure). This rule should eliminate the possibility of the influence of web elements by already implemented web design localization. 
For content analysis, it was also necessary to choose web elements that would be tracked on the website. For this purpose, the most important web elements that could be found on a common website were selected. To select such web elements, a discussion was conducted with three experts within the field of website development with more than seven years' experience (Cermak, 2017). The result is based on the consensus of these three specialists. Altogether, 42 elements were identified:

Logo; Sidebar; Navigation - vertical, horizontal, multi-level, iconic, pictorial; Banner or slider - static, animated, full-width, small; Contact - e-mail, telephone, address; Map; Form; Online chat; News - headline, image, annotation, text; Events; Newsletter; Search - complete, just search icon; Reference; Forum; FAQ; Links section; Picture; Video; Sitemap; Slogan or motto of the company; Symbols - general and culturally (nationally) specific; Headlines - h1, h2, h3 ${ }^{5}$; Personalization; https.

for the presence of each element on the homepage was monitored the presence. Other monitored elements were social networks and general site properties (information density, overall colour, saturation/brilliance, text to graphics ratio and overall complexity of web design). The evaluation of these characteristics was based on the Likert scale 1 to 5 , where 1 means the lowest value for a given property and 5 the highest value.

To derive some generalized conclusions, we must combine the results with the primary, secondary and tertiary cultural dimensions. To obtain these generalizable conclusions, it was first necessary to determine the degree of element depiction depending on the cultural dimension.

\section{The process was as follows:}

1) Cultural dimensions that we previously marked as primary, secondary and tertiary were given a score as follows: primary $=6$ points, secondary $=3$ points, tertiary $=1.5$ points (in the cases when the value of the difference from the average is equal to or greater than 24), 1 point (if the difference value was within the range of 20 to 23 points $)^{6}$

2) For every cultural dimension, the value of a difference was calculated between the values of displayed elements within countries with high and low value of this dimension. Only countries with primary, secondary or tertiary dimensions were counted.

3) The value of difference was calculated for such pairs. This value gives us the assessment of a given cultural dimension.

4) The multiple of values from point 1 and 3 was used as a scale to rank the value from point 2.

5) The degree of element depiction was determined as an average value from point 2 using weights from point 4.

In this way, all elements were evaluated depending on the cultural dimensions.

\footnotetext{
${ }^{5}$ Headlines were determined based on their appropriate marking with tags in the source code. Thus, if the page had optically highlighted text that was not marked by a tag, this headline was ignored. This limitation had to applied to ensure consensus within the differentiation of headlines and another highlighted text. At the same time, these elements could not be omitted because they are one of the most fundamental elements of each website.

${ }^{6}$ This nuance in the score was made to achieve higher accuracy within the assessment of importance. The second, more important, reason was the fact that the values of tertiary dimensions are closer to the average values and therefore there is a higher probability of interference with other cultural dimensions. The main emphasis was therefore on primary dimensions.
} 


\section{Results}

Table 3 shows the percentage in which web elements occurred on websites. Some of the determined elements did not occur at all or in a very small number. No statements could be made regarding such elements. These elements were therefore excluded ${ }^{7}$ from further investigation: online chat, https, website personalization, forum, FAQ, displaying of icon search without search field, displaying the text of news and events. From all surveyed countries, only Japan had a 16\% presence of FAQ and 12\% presence of events. The type of search where only an icon is shown was for the purpose of the following analysis merged under a general term of search because this division proved to be irrelevant.

\begin{tabular}{|c|c|c|c|c|c|c|c|c|c|c|c|c|c|c|c|c|c|c|}
\hline \multirow{2}{*}{\begin{tabular}{|l} 
Elements \\
Vertical nav. \\
\end{tabular}} & \multicolumn{2}{|c|}{ Czechia } & \multicolumn{2}{|c|}{ US } & \multicolumn{2}{|c|}{ China } & \multicolumn{2}{|c|}{ Chile } & \multicolumn{2}{|c|}{ S.A. } & \multicolumn{2}{|c|}{ Nigeria } & \multicolumn{2}{|c|}{ Latvia } & \multicolumn{2}{|c|}{ Japan } & \multicolumn{2}{|c|}{ Austria } \\
\hline & $88 \%$ & $1 \%$ & $84 \%$ & $-3 \%$ & & $1 \%$ & $82 \%$ & & $92 \%$ & $5 \%$ & $98 \%$ & $11 \%$ & & & & $-3 \%$ & & $1 \%$ \\
\hline Horizon & & $2 \%$ & & $4 \%$ & $2 \%$ & $-6 \%$ & $6 \%$ & $-2 \%$ & & $0 \%$ & $10 \%$ & $-8 \%$ & $4 \%$ & $-4 \%$ & $6 \%$ & $8 \%$ & & $6 \%$ \\
\hline & $\%$ & $\%$ & & $22 \%$ & $\%$ & & $2 \%$ & $-2 \%$ & & $-4 \%$ & & & & & & & & \\
\hline & $4 \%$ & $3 \%$ & & $-5 \%$ & $8 \%$ & $1 \%$ & $4 \%$ & $-13 \%$ & $50 \%$ & $3 \%$ & $48 \%$ & $1 \%$ & $38 \%$ & $-9 \%$ & $74 \%$ & $27 \%$ & $4 \%$ & $-3 \%$ \\
\hline & $4 \%$ & $0 \%$ & & $4 \%$ & $8 \%$ & $-6 \%$ & $14 \%$ & $-10 \%$ & $6 \%$ & $-18 \%$ & $30 \%$ & $6 \%$ & $28 \%$ & $4 \%$ & $46 \%$ & $22 \%$ & & $8 \%$ \\
\hline & $\%$ & $6 \%$ & & $-4 \%$ & $4 \%$ & $-2 \%$ & $54 \%$ & $8 \%$ & $28 \%$ & $-18 \%$ & $38 \%$ & $-8 \%$ & $58 \%$ & $12 \%$ & $30 \%$ & $-16 \%$ & $6 \%$ & 200 \\
\hline & $3 \%$ & $3 \%$ & & $3 \%$ & $82 \%$ & $11 \%$ & $90 \%$ & $19 \%$ & $18 \%$ & $-23 \%$ & $60 \%$ & & $2 \%$ & $1 \%$ & $64 \%$ & $-7 \%$ & $4 \%$ & \\
\hline & $4 \%$ & $8 \%$ & $8 \%$ & $12 \%$ & $54 \%$ & $-2 \%$ & $72 \%$ & $16 \%$ & $26 \%$ & $-30 \%$ & $48 \%$ & $-8 \%$ & $52 \%$ & $-4 \%$ & $54 \%$ & $-2 \%$ & $6 \%$ & $0 \%$ \\
\hline & $6 \%$ & $2 \%$ & $70 \%$ & $26 \%$ & $34 \%$ & $-10 \%$ & $52 \%$ & $8 \%$ & $40 \%$ & $-4 \%$ & $40 \%$ & $-4 \%$ & $22 \%$ & $-22 \%$ & $46 \%$ & $2 \%$ & $44 \%$ & $\%$ \\
\hline & $8 \%$ & $4 \%$ & & $-4 \%$ & $4 \%$ & $0 \%$ & $2 \%$ & $-2 \%$ & $6 \%$ & $2 \%$ & $8 \%$ & $4 \%$ & $6 \%$ & $2 \%$ & $0 \%$ & $-4 \%$ & $4 \%$ & \\
\hline & $14 \%$ & $1 \%$ & $26 \%$ & $13 \%$ & $10 \%$ & $-3 \%$ & $6 \%$ & \begin{tabular}{|l|}
$-7 \%$ \\
\end{tabular} & $10 \%$ & $-3 \%$ & $24 \%$ & $11 \%$ & $2 \%$ & $-11 \%$ & $2 \%$ & $-11 \%$ & $24 \%$ & $11 \%$ \\
\hline & $2 \%$ & $0 \%$ & & $8 \%$ & $14 \%$ & $-8 \%$ & $20 \%$ & $-2 \%$ & $16 \%$ & $-6 \%$ & $8 \%$ & & $30 \%$ & $8 \%$ & $40 \%$ & $18 \%$ & $20 \%$ & $-2 \%$ \\
\hline & $64 \%$ & $-2 \%$ & $68 \%$ & $2 \%$ & $80 \%$ & $14 \%$ & $72 \%$ & $6 \%$ & $62 \%$ & $-4 \%$ & $84 \%$ & $18 \%$ & $48 \%$ & $-18 \%$ & $54 \%$ & $-12 \%$ & $62 \%$ & $-4 \%$ \\
\hline & $34 \%$ & $-1 \%$ & $34 \%$ & $-1 \%$ & $36 \%$ & $1 \%$ & $40 \%$ & $5 \%$ & $38 \%$ & $3 \%$ & $34 \%$ & $-1 \%$ & $46 \%$ & $11 \%$ & $26 \%$ & $-9 \%$ & $30 \%$ & $-5 \%$ \\
\hline & $6 \%$ & $-12 \%$ & $8 \%$ & $-10 \%$ & $8 \%$ & $-10 \%$ & $4 \%$ & $-14 \%$ & $40 \%$ & $22 \%$ & $10 \%$ & $-8 \%$ & $14 \%$ & $-4 \%$ & $60 \%$ & $42 \%$ & $14 \%$ & $-4 \%$ \\
\hline & $8 \%$ & $7 \%$ & $16 \%$ & $1 \%$ & $18 \%$ & $3 \%$ & $14 \%$ & $-1 \%$ & $38 \%$ & $23 \%$ & $10 \%$ & $-5 \%$ & $6 \%$ & $-9 \%$ & $16 \%$ & $1 \%$ & $8 \%$ & $-7 \%$ \\
\hline & $2 \%$ & $-1 \%$ & & $3 \%$ & $0 \%$ & $-3 \%$ & $4 \%$ & $1 \%$ & $2 \%$ & $-1 \%$ & $8 \%$ & $5 \%$ & $4 \%$ & $1 \%$ & $0 \%$ & $-3 \%$ & $4 \%$ & $1 \%$ \\
\hline & $2 \%$ & $5 \%$ & $\%$ & $11 \%$ & $34 \%$ & $-3 \%$ & $40 \%$ & $3 \%$ & $8 \%$ & $1 \%$ & $32 \%$ & $-5 \%$ & $38 \%$ & $1 \%$ & $38 \%$ & $1 \%$ & $34 \%$ & $-3 \%$ \\
\hline & $2 \%$ & $6 \%$ & $40 \%$ & $4 \%$ & $32 \%$ & $-4 \%$ & $28 \%$ & $-8 \%$ & $38 \%$ & $2 \%$ & $24 \%$ & $-12 \%$ & $30 \%$ & $-6 \%$ & $46 \%$ & $10 \%$ & $48 \%$ & $12 \%$ \\
\hline & $8 \%$ & $0 \%$ & 100 & $2 \%$ & $98 \%$ & $0 \%$ & $98 \%$ & $0 \%$ & $100 \%$ & $2 \%$ & $98 \%$ & $0 \%$ & $96 \%$ & $-2 \%$ & $100 \%$ & $2 \%$ & $92 \%$ & $-6 \%$ \\
\hline & $0 \%$ & $0 \%$ & & $0 \%$ & $0 \%$ & $0 \%$ & $2 \%$ & $2 \%$ & $2 \%$ & $2 \%$ & $0 \%$ & $\%$ & $0 \%$ & $0 \%$ & $0 \%$ & $0 \%$ & $0 \%$ & $0 \%$ \\
\hline & $46 \%$ & $-4 \%$ & $\%$ & $8 \%$ & $54 \%$ & $4 \%$ & $36 \%$ & $-14 \%$ & $8 \%$ & $8 \%$ & $46 \%$ & $-4 \%$ & $26 \%$ & $-24 \%$ & $76 \%$ & $26 \%$ & $54 \%$ & $4 \%$ \\
\hline & $0 \%$ & $0 \%$ & & $0 \%$ & $0 \%$ & $0 \%$ & $0 \%$ & $0 \%$ & & $0 \%$ & $0 \%$ & & $0 \%$ & $0 \%$ & $0 \%$ & $0 \%$ & $0 \%$ & $0 \%$ \\
\hline & & & & & & $0 \%$ & $\%$ & & & & & & $0 \%$ & & $0 \%$ & $\%$ & 0 & $0 \%$ \\
\hline & & & & $3 \%$ & $0 \%$ & $-3 \%$ & $0 \%$ & $-3 \%$ & & $-1 \%$ & $4 \%$ & & $0 \%$ & $-3 \%$ & $16 \%$ & $3 \%$ & $0 \%$ & $-3 \%$ \\
\hline & & & & $-4 \%$ & $58 \%$ & $14 \%$ & $28 \%$ & $-16 \%$ & & $16 \%$ & $18 \%$ & $-26 \%$ & $28 \%$ & $-16 \%$ & $78 \%$ & $34 \%$ & $28 \%$ & -16 \\
\hline & $3 \%$ & $7 \%$ & & $3 \%$ & $34 \%$ & $3 \%$ & $30 \%$ & $-1 \%$ & $46 \%$ & $15 \%$ & $12 \%$ & $-19 \%$ & $28 \%$ & $-3 \%$ & $30 \%$ & $-1 \%$ & $26 \%$ & $-5 \%$ \\
\hline & & & & $\%$ & $14 \%$ & $-7 \%$ & $16 \%$ & $-5 \%$ & & $17 \%$ & $8 \%$ & & $16 \%$ & $5 \%$ & $22 \%$ & $1 \%$ & $14 \%$ & $-7 \%$ \\
\hline & & & & $-1 \%$ & $0 \%$ & $-1 \%$ & $0 \%$ & $-1 \%$ & & $-1 \%$ & $4 \%$ & $\%$ & $0 \%$ & $-1 \%$ & $2 \%$ & $1 \%$ & $2 \%$ & $1 \%$ \\
\hline & & & & $-2 \%$ & $0 \%$ & $-4 \%$ & $0 \%$ & $-4 \%$ & $4 \%$ & $0 \%$ & $6 \%$ & & $0 \%$ & $-4 \%$ & $12 \%$ & $8 \%$ & $2 \%$ & $-2 \%$ \\
\hline & $12 \%$ & $-1 \%$ & & $-3 \%$ & $14 \%$ & $1 \%$ & $12 \%$ & $-1 \%$ & $16 \%$ & $3 \%$ & $4 \%$ & $-9 \%$ & $0 \%$ & $-13 \%$ & $40 \%$ & $27 \%$ & $10 \%$ & $-3 \%$ \\
\hline & $84 \%$ & $-2 \%$ & $70 \%$ & $-16 \%$ & $76 \%$ & $-10 \%$ & $86 \%$ & $0 \%$ & $84 \%$ & $-2 \%$ & $96 \%$ & $10 \%$ & $88 \%$ & $2 \%$ & $100 \%$ & $14 \%$ & $94 \%$ & $8 \%$ \\
\hline & $12 \%$ & $-1 \%$ & $14 \%$ & $1 \%$ & $14 \%$ & $1 \%$ & $22 \%$ & $9 \%$ & $18 \%$ & $5 \%$ & $4 \%$ & $-9 \%$ & $8 \%$ & $-5 \%$ & $18 \%$ & $5 \%$ & $4 \%$ & $-9 \%$ \\
\hline & $36 \%$ & $14 \%$ & $40 \%$ & $18 \%$ & $4 \%$ & $-18 \%$ & $20 \%$ & $-2 \%$ & $14 \%$ & $-8 \%$ & $14 \%$ & $-8 \%$ & $28 \%$ & $6 \%$ & $22 \%$ & $0 \%$ & $16 \%$ & $-6 \%$ \\
\hline h1 & $62 \%$ & $18 \%$ & $44 \%$ & $0 \%$ & $22 \%$ & $-22 \%$ & $30 \%$ & $-14 \%$ & $34 \%$ & $-10 \%$ & $30 \%$ & $-14 \%$ & $50 \%$ & $6 \%$ & $64 \%$ & $20 \%$ & $58 \%$ & $14 \%$ \\
\hline h2 & $70 \%$ & $14 \%$ & $70 \%$ & $14 \%$ & $38 \%$ & $-18 \%$ & $38 \%$ & $-18 \%$ & $54 \%$ & $-2 \%$ & $38 \%$ & $-18 \%$ & $66 \%$ & $10 \%$ & $78 \%$ & $22 \%$ & $48 \%$ & $-8 \%$ \\
\hline h3 & $64 \%$ & $18 \%$ & $40 \%$ & $-6 \%$ & $26 \%$ & $-20 \%$ & $40 \%$ & $-6 \%$ & $58 \%$ & $12 \%$ & $50 \%$ & $4 \%$ & $46 \%$ & $0 \%$ & $56 \%$ & $10 \%$ & $38 \%$ & $-8 \%$ \\
\hline & $30 \%$ & $-5 \%$ & $50 \%$ & $15 \%$ & $42 \%$ & $7 \%$ & $22 \%$ & $-13 \%$ & $12 \%$ & $-23 \%$ & $26 \%$ & $-9 \%$ & $22 \%$ & $-13 \%$ & $68 \%$ & $33 \%$ & $40 \%$ & $5 \%$ \\
\hline
\end{tabular}

\footnotetext{
${ }^{7}$ These elements should be part of other types of websites. Https is typically used when a website contains a client section, the ability to login to your account, etc. That is typically the case of e-shops. Online forms, FAQs, forums, and events could be expected within a selected cross-section of websites, but this expectation was not confirmed. Online forms, forums and FAQs are probably more typical for websites with online services such as hosting. Events would then be expected mainly at sites of various organizations and government units.
} 


\begin{tabular}{|c|c|c|c|c|c|c|c|c|c|c|c|c|c|c|c|c|c|c|}
\hline Ele & \multicolumn{2}{|c|}{ Czechia } & \multicolumn{2}{|c|}{ US } & \multicolumn{2}{|c|}{ China } & \multicolumn{2}{|c|}{ Chile } & \multicolumn{2}{|c|}{ S.A. } & \multicolumn{2}{|c|}{ Nigeria } & \multicolumn{2}{|c|}{ Latvia } & \multicolumn{2}{|c|}{ Japan } & \multicolumn{2}{|c|}{ Austria } \\
\hline & $76 \%$ & $21 \%$ & $6 \%$ & $-9 \%$ & $50 \%$ & $-5 \%$ & $62 \%$ & $7 \%$ & $2 \%$ & $7 \%$ & $32 \%$ & & $42 \%$ & $-13 \%$ & $74 \%$ & $19 \%$ & $48 \%$ & $-7 \%$ \\
\hline ym & $24 \%$ & $-4 \%$ & $14 \%$ & $-14 \%$ & $50 \%$ & $22 \%$ & $32 \%$ & $4 \%$ & $36 \%$ & $8 \%$ & $6 \%$ & $-22 \%$ & $6 \%$ & $-22 \%$ & $56 \%$ & $28 \%$ & $26 \%$ & -29 \\
\hline
\end{tabular}

Tab. 3. The frequency of presence of website elements in each country. The left columns for each country show the total percentage value of depiction. The right columns provide the percentage difference of values compared to average value. Higher differences - above $20 \%$ - are highlighted in bold. Source: Author.

The Table 3 shows the presence of website elements in each country. The left column represents the total percentage value. The right column represents the percentage difference in values compared to the average. A closer look at the right column shows that the biggest differences are in the use of multi-level navigation, contact details, small banners, depiction of news, headlines, links section, slogan and symbols. On the other hand, there is a similarity in the use of the main navigation, banner (or slider), search, references, sidebar, sitemap, images and videos.

It is easy to observe that current websites have some common features, which undoubtedly stems from the principles of website development as well as from the trends and best practices that prevail in this field. On the other hand, despite these linking attributes, websites are specifically influenced by the country, that is, by the culture of the country in which they were created.

Table 4 shows the use of social networks on websites. Results show that the most used social networks are Facebook, followed by Twitter and Google+. Other popular social networks are YouTube, Instagram, Pinterest and LinkedIn. Among the companies engaged in accommodation and hospitality, TripAdvisor is popular.

\begin{tabular}{|l|c|c|c|c|c|c|c|c|c|}
\hline & Czechia & US & China & Chile & S.A. & Nig. & Lat. & Jap. & Aus. \\
\hline Facebook & $56 \%$ & $78 \%$ & $14 \%$ & $78 \%$ & $76 \%$ & $60 \%$ & $58 \%$ & $44 \%$ & $52 \%$ \\
\hline Twitter & $16 \%$ & $70 \%$ & $10 \%$ & $54 \%$ & $74 \%$ & $52 \%$ & $48 \%$ & $36 \%$ & $18 \%$ \\
\hline G+ & $24 \%$ & $40 \%$ & $4 \%$ & $24 \%$ & $36 \%$ & $18 \%$ & $18 \%$ & $16 \%$ & $16 \%$ \\
\hline YouTube & $10 \%$ & $10 \%$ & $0 \%$ & $18 \%$ & $38 \%$ & $12 \%$ & $6 \%$ & $4 \%$ & $2 \%$ \\
\hline Instagram & $6 \%$ & $16 \%$ & $2 \%$ & $10 \%$ & $24 \%$ & $14 \%$ & $8 \%$ & $6 \%$ & $0 \%$ \\
\hline Pinterest & $6 \%$ & $16 \%$ & $2 \%$ & $8 \%$ & $12 \%$ & $6 \%$ & $10 \%$ & $2 \%$ & $8 \%$ \\
\hline Vimeo & $2 \%$ & $2 \%$ & $0 \%$ & $4 \%$ & $0 \%$ & $0 \%$ & $2 \%$ & $0 \%$ & $2 \%$ \\
\hline LinkedIn & $4 \%$ & $16 \%$ & $2 \%$ & $14 \%$ & $14 \%$ & $8 \%$ & $2 \%$ & $0 \%$ & $4 \%$ \\
\hline TripAdvisor & $10 \%$ & $10 \%$ & $8 \%$ & $22 \%$ & $8 \%$ & $8 \%$ & $10 \%$ & $4 \%$ & $10 \%$ \\
\hline Yelp & $4 \%$ & $4 \%$ & $0 \%$ & $0 \%$ & $0 \%$ & $0 \%$ & $0 \%$ & $0 \%$ & $2 \%$ \\
\hline Foursquare & $2 \%$ & $0 \%$ & $0 \%$ & $0 \%$ & $4 \%$ & $2 \%$ & $2 \%$ & $0 \%$ & $0 \%$ \\
\hline Flickr & $0 \%$ & $2 \%$ & $2 \%$ & $2 \%$ & $4 \%$ & $0 \%$ & $0 \%$ & $0 \%$ & $0 \%$ \\
\hline StumbleUpon & $0 \%$ & $2 \%$ & $0 \%$ & $0 \%$ & $2 \%$ & $0 \%$ & $2 \%$ & $0 \%$ & $0 \%$ \\
\hline Behance & $0 \%$ & $0 \%$ & $0 \%$ & $0 \%$ & $2 \%$ & $0 \%$ & $2 \%$ & $0 \%$ & $0 \%$ \\
\hline Houzz & $0 \%$ & $2 \%$ & $0 \%$ & $0 \%$ & $0 \%$ & $2 \%$ & $2 \%$ & $0 \%$ & $0 \%$ \\
\hline Zomato & $2 \%$ & $0 \%$ & $0 \%$ & $0 \%$ & $0 \%$ & $0 \%$ & $0 \%$ & $0 \%$ & $0 \%$ \\
\hline Weibo & $0 \%$ & $0 \%$ & $20 \%$ & $0 \%$ & $0 \%$ & $0 \%$ & $0 \%$ & $0 \%$ & $0 \%$ \\
\hline QQ (im.qq.com) & $0 \%$ & $0 \%$ & $20 \%$ & $0 \%$ & $0 \%$ & $0 \%$ & $0 \%$ & $0 \%$ & $0 \%$ \\
\hline WeChat & $0 \%$ & $0 \%$ & $12 \%$ & $0 \%$ & $0 \%$ & $0 \%$ & $0 \%$ & $0 \%$ & $0 \%$ \\
\hline Hostelbookers & $0 \%$ & $0 \%$ & $0 \%$ & $2 \%$ & $0 \%$ & $0 \%$ & $0 \%$ & $0 \%$ & $0 \%$ \\
\hline MySpace & $0 \%$ & $0 \%$ & $0 \%$ & $0 \%$ & $4 \%$ & $0 \%$ & $0 \%$ & $0 \%$ & $0 \%$ \\
\hline iTunes & $0 \%$ & $0 \%$ & $0 \%$ & $0 \%$ & $2 \%$ & $0 \%$ & $0 \%$ & $0 \%$ & $0 \%$ \\
\hline Snapchat & $0 \%$ & $0 \%$ & $0 \%$ & $0 \%$ & $2 \%$ & $0 \%$ & $0 \%$ & $0 \%$ & $0 \%$ \\
\hline Draugiem.lv & $0 \%$ & $0 \%$ & $0 \%$ & $0 \%$ & $0 \%$ & $0 \%$ & $18 \%$ & $0 \%$ & $0 \%$ \\
\hline Hatena.ne.jp & $0 \%$ & $0 \%$ & $0 \%$ & $0 \%$ & $0 \%$ & $0 \%$ & $0 \%$ & $4 \%$ & $0 \%$ \\
\hline Line.me & $0 \%$ & $0 \%$ & $0 \%$ & $0 \%$ & $0 \%$ & $0 \%$ & $0 \%$ & $6 \%$ & $0 \%$ \\
\hline Xing.com & $0 \%$ & $0 \%$ & $0 \%$ & $0 \%$ & $0 \%$ & $0 \%$ & $0 \%$ & $0 \%$ & $2 \%$ \\
\hline
\end{tabular}

Tab. 4. The use of social networks on websites from selected countries. Source: Author. 
The biggest differences are on Chinese websites. The previously mentioned social networks are used only by a fraction of companies on Chinese websites compared to the rest of the countries. The reason is mainly that Chinese companies use local favourite social networks and forms of communication. An example might be the use of Weibo, the microblogging Chinese equivalent of Twitter, or the use of locally favourite chat applications QQ or WeChat. In China, it is also very frequent to use $\mathrm{QR} \operatorname{codes}^{8}$ that lead directly to a company's profile.

Minor differences can be found among other states. In general, social networks are used slightly less in the Czech Republic and Austria, especially Twitter is not so popular there. A higher use of Google+ can be noticed in the US; in Saudi Arabia there is a higher use rate of YouTube and Instagram. It is worth mentioning the use of the network Draugiem.lv in Latvia. This is a local version of the social network Frype.com. This social network was recorded only on Latvian websites.

It is quite straightforward that presence on social networking sites is related to the target audience and that there are differences regarding the most popular social networks across the world. The results are in line with these general assumptions and, moreover, they can help to provide an insight regarding the importance of social networks within selected countries.

A general website feature overview is shown in Table 5. The results confirm that there are differences between states. The highest information density can be found mainly in Japan, the lowest in Chile and Latvia. The highest overall colour was found in Chile, the lowest in Saudi Arabia. Saturation was also the highest in Chile, followed by Nigeria, at the opposite pole were websites in Saudi Arabia. The graphics to text ratio was the highest in Chile and the largest text to graphics ratio was in the US and Austria. The complicated or more complex structure was on websites from China and Japan, a simple structure can be found mainly on websites from Chile, followed by the US and Latvia.

\begin{tabular}{|l|c|c|c|c|c|c|c|c|c|c|}
\hline & Czechia & US & China & Chile & S.A. & Nig. & Lat. & Jap. & Aus. & Average \\
\hline Information density & 2,06 & 1,46 & 2,28 & 1,28 & 1,74 & 1,58 & 1,32 & 3 & 1,96 & 1,85 \\
\hline Overall colour & 2,06 & 1,94 & 2,68 & 3 & 1,77 & 2,32 & 1,98 & 2,34 & 1,98 & 2,23 \\
\hline Saturation/brilliance & 3,26 & 3,12 & 2,98 & 3,8 & 2,19 & 3,54 & 2,68 & 2,7 & 3,06 & 3,04 \\
\hline Text to graphics ratio & 3,2 & 2,88 & 3,66 & 4,28 & 3,23 & 3 & 3,24 & 3,16 & 2,9 & 3,28 \\
\hline Web design complexity & 1,68 & 1,32 & 2,28 & 1,14 & 1,4 & 1,62 & 1,36 & 2,18 & 1,38 & 1,6 \\
\hline
\end{tabular}

Tab. 5. Differences in general features of websites. Each website was evaluated on Likert scale from 1 to 5.1 means that a feature was not observed, and 5 means that it was typical for the given website. The displayed values represent averages of all analysed websites. Source: Author.

\section{Discussion}

According to the approach described in the last part of the methodology section, Table 6 was created, showing complete results.

\begin{tabular}{|l|c|c|c|c|c|c|}
\hline & IND & UA & PD & LTO & MAS & IVR \\
\hline Vertical nav. & $-5 \%$ & $-3 \%$ & $3 \%$ & $-9 \%$ & $5 \%$ & $15 \%$ \\
\hline Horizontal nav. & $7 \%$ & $8 \%$ & $-8 \%$ & $5 \%$ & $10 \%$ & $-4 \%$ \\
\hline Multi-level nav. & $16 \%$ & $-12 \%$ & $-2 \%$ & $-9 \%$ & $3 \%$ & $14 \%$ \\
\hline
\end{tabular}

\footnotetext{
${ }^{8}$ About $40 \%$ of Chinese websites contained a QR code, which is typically directed to any of the chat platforms or other social networks. QR codes were also recorded on websites from Chile and Japan (but in both cases only in $4 \%$ of websites).
} 


\begin{tabular}{|c|c|c|c|c|c|c|}
\hline & IND & UA & PD & LTO & MAS & IVR \\
\hline Iconic nav. & $-4 \%$ & $0 \%$ & $2 \%$ & $9 \%$ & $26 \%$ & $7 \%$ \\
\hline Pictorial nav. & $5 \%$ & $4 \%$ & $-19 \%$ & $-1 \%$ & $13 \%$ & $5 \%$ \\
\hline E-mail & $2 \%$ & $0 \%$ & $-30 \%$ & $2 \%$ & $-18 \%$ & $-16 \%$ \\
\hline Phone & $0 \%$ & $-9 \%$ & $-24 \%$ & $13 \%$ & $-5 \%$ & $-15 \%$ \\
\hline Address & $15 \%$ & $4 \%$ & $-25 \%$ & $3 \%$ & $2 \%$ & $-5 \%$ \\
\hline Form & $25 \%$ & $14 \%$ & $-1 \%$ & $-6 \%$ & $20 \%$ & $13 \%$ \\
\hline Newsletter & $13 \%$ & $-3 \%$ & $-12 \%$ & $-17 \%$ & $5 \%$ & $19 \%$ \\
\hline Banner - static & $15 \%$ & $11 \%$ & $-5 \%$ & $11 \%$ & $4 \%$ & $-17 \%$ \\
\hline Banner - animated & $-9 \%$ & $-16 \%$ & $7 \%$ & $-11 \%$ & $7 \%$ & $26 \%$ \\
\hline Banner - full-width & $-2 \%$ & $-1 \%$ & $8 \%$ & $-1 \%$ & $-17 \%$ & $-9 \%$ \\
\hline Banner - small & $-5 \%$ & $18 \%$ & $11 \%$ & $14 \%$ & $31 \%$ & $-2 \%$ \\
\hline Search & $-2 \%$ & $3 \%$ & $18 \%$ & $-2 \%$ & $5 \%$ & $6 \%$ \\
\hline Reference & $11 \%$ & $4 \%$ & $3 \%$ & $0 \%$ & $-1 \%$ & $-5 \%$ \\
\hline Sidebar & $8 \%$ & $5 \%$ & $-15 \%$ & $10 \%$ & $15 \%$ & $-7 \%$ \\
\hline Logo & $1 \%$ & $1 \%$ & $7 \%$ & $0 \%$ & $2 \%$ & $1 \%$ \\
\hline Links section & $5 \%$ & $-3 \%$ & $-4 \%$ & $12 \%$ & $40 \%$ & $11 \%$ \\
\hline News - headline & $-8 \%$ & $-10 \%$ & $15 \%$ & $42 \%$ & $35 \%$ & $-20 \%$ \\
\hline News - picture & $1 \%$ & $0 \%$ & $9 \%$ & $17 \%$ & $1 \%$ & $-18 \%$ \\
\hline News - annotation & $5 \%$ & $10 \%$ & $12 \%$ & $8 \%$ & $4 \%$ & $-9 \%$ \\
\hline Sitemap & $-4 \%$ & $6 \%$ & $2 \%$ & $17 \%$ & $28 \%$ & $-1 \%$ \\
\hline Picture & $-11 \%$ & $14 \%$ & $-7 \%$ & $-8 \%$ & $9 \%$ & $12 \%$ \\
\hline Video & $-2 \%$ & $5 \%$ & $12 \%$ & $9 \%$ & $5 \%$ & $-6 \%$ \\
\hline Map & $28 \%$ & $17 \%$ & $-1 \%$ & $-6 \%$ & $-6 \%$ & $-8 \%$ \\
\hline h1 & $17 \%$ & $22 \%$ & $-26 \%$ & $6 \%$ & $11 \%$ & $-13 \%$ \\
\hline h2 & $28 \%$ & $17 \%$ & $-1 \%$ & $9 \%$ & $6 \%$ & $-20 \%$ \\
\hline h3 & $2 \%$ & $24 \%$ & $14 \%$ & $-10 \%$ & $6 \%$ & $9 \%$ \\
\hline Slogan & $18 \%$ & $-10 \%$ & $-23 \%$ & $19 \%$ & $35 \%$ & $-2 \%$ \\
\hline Symbols - general & $-7 \%$ & $16 \%$ & $7 \%$ & $25 \%$ & $22 \%$ & $-14 \%$ \\
\hline Symbols - cult. & $-24 \%$ & $-13 \%$ & $2 \%$ & $42 \%$ & $37 \%$ & $-13 \%$ \\
\hline
\end{tabular}

Tab. 6. The degree of use of elements on websites with dependence on cultural dimensions: Power distance (PD), Individualism vs collectivism (IND), Masculinity vs femininity (MAS), Uncertainty avoidance (UA), Long term orientation (LTO), Indulgence vs restraint (IVR). Values were determined on the basis of the impact of primary $(P)$, secondary $(S)$ and tertiary $(T)$ cultural dimensions. Source: Author.

The Table 6 shows that some elements are dependent on cultural dimensions more than others. This divides elements into two groups. The first are culturally sensitive elements, the second are elements that are not. This is determined unambiguously by the fact that the elements belonging to the second group are essential for any website.

To obtain a more comprehensive evaluation, an additional method of calculation was used. The second method simply compares element depictions for a given cultural dimension, depending on the value of cultural dimension difference from the average value. ${ }^{9}$ By

\footnotetext{
${ }^{9}$ Value 50 was taken as the average value because the value range for cultural dimensions is from 0 to 100.
} 
multiplying this value and the percentage rate of element depiction difference, and then averaging these values, the degree of element occurrence was obtained. The results of this calculation method were very similar to those of the first calculation. For a more detailed comparison of these two approaches, see Table 7 with normalized values.

\begin{tabular}{|c|c|c|c|c|c|c|c|c|c|c|c|c|}
\hline & \multicolumn{6}{|c|}{ General } & \multicolumn{6}{|c|}{ Based on $P, S$ and $T$ dimensions } \\
\hline & IND & UA & PD & LTO & MAS & IVR & IND & UA & PD & LTO & MAS & IVR \\
\hline Vertical nav. & $-0,17$ & $-0,06$ & 0,20 & $-0,18$ & 0,16 & 0,18 & $-0,12$ & $-0,07$ & 0,07 & $-0,21$ & 0,12 & 0,36 \\
\hline Horizontal nav. & 0,18 & 0,16 & $-0,24$ & 0,12 & 0,23 & 0,01 & 0,17 & 0,19 & $-0,19$ & 0,12 & 0,23 & $-0,09$ \\
\hline Multi-level nav. & 0,22 & $-0,42$ & $-0,01$ & $-0,44$ & 0,12 & 0,33 & 0,37 & $-0,28$ & $-0,04$ & $-0,20$ & 0,08 & 0,32 \\
\hline Iconic nav. & $-0,11$ & 0,19 & 0,12 & 0,40 & 0,64 & $-0,06$ & $-0,09$ & 0,00 & 0,05 & 0,21 & 0,62 & 0,16 \\
\hline Pictorial nav. & 0,24 & 0,13 & $-0,42$ & 0,39 & 0,36 & $-0,06$ & 0,11 & 0,10 & $-0,44$ & $-0,03$ & 0,31 & 0,12 \\
\hline E-mail & 0,27 & $-0,06$ & $-0,66$ & 0,14 & $-0,40$ & $-0,13$ & 0,04 & $-0,01$ & $-0,70$ & 0,04 & $-0,43$ & $-0,37$ \\
\hline Phone & 0,06 & $-0,16$ & $-0,51$ & 0,19 & $-0,21$ & $-0,02$ & 0,00 & $-0,21$ & $-0,56$ & 0,31 & $-0,12$ & $-0,34$ \\
\hline Address & 0,39 & $-0,04$ & $-0,68$ & 0,06 & $-0,07$ & 0,13 & 0,35 & 0,10 & $-0,58$ & 0,08 & 0,05 & $-0,12$ \\
\hline Form & 0,32 & 0,04 & $-0,21$ & $-0,45$ & 0,33 & 0,54 & 0,59 & 0,33 & $-0,03$ & $-0,15$ & 0,47 & 0,31 \\
\hline Newsletter & 0,20 & $-0,24$ & $-0,19$ & $-0,42$ & 0,22 & 0,42 & 0,30 & $-0,06$ & $-0,28$ & $-0,39$ & 0,13 & 0,45 \\
\hline Banner - static & 0,41 & 0,21 & $-0,34$ & 0,35 & 0,08 & $-0,23$ & 0,35 & 0,25 & $-0,12$ & 0,26 & 0,10 & $-0,40$ \\
\hline Banner - animated & $-0,40$ & $-0,35$ & 0,38 & $-0,41$ & 0,12 & 0,41 & $-0,21$ & $-0,38$ & 0,17 & $-0,25$ & 0,16 & 0,61 \\
\hline Banner - full-width & $-0,01$ & $-0,06$ & 0,10 & $-0,09$ & $-0,40$ & $-0,13$ & $-0,04$ & $-0,02$ & 0,18 & $-0,03$ & $-0,40$ & $-0,20$ \\
\hline Banner - small & $-0,17$ & 0,60 & 0,22 & 0,49 & 0,73 & $-0,14$ & $-0,13$ & 0,42 & 0,26 & 0,34 & 0,74 & $-0,04$ \\
\hline Search & $-0,23$ & 0,04 & 0,42 & $-0,32$ & 0,09 & 0,19 & $-0,04$ & 0,07 & 0,43 & $-0,05$ & 0,11 & 0,14 \\
\hline Reference & 0,18 & 0,00 & $-0,07$ & $-0,12$ & $-0,05$ & 0,07 & 0,26 & 0,10 & 0,07 & 0,01 & $-0,03$ & $-0,11$ \\
\hline Sidebar & 0,24 & 0,16 & $-0,33$ & 0,30 & 0,40 & $-0,07$ & 0,18 & 0,11 & $-0,36$ & 0,24 & 0,35 & $-0,17$ \\
\hline Logo & $-0,02$ & 0,01 & 0,12 & $-0,03$ & 0,02 & 0,01 & 0,03 & 0,01 & 0,17 & 0,01 & 0,05 & 0,03 \\
\hline Links section & $-0,04$ & 0,11 & 0,05 & 0,27 & 0,99 & 0,17 & 0,11 & $-0,06$ & $-0,09$ & 0,29 & 0,95 & 0,26 \\
\hline News - headline & $-0,17$ & 0,27 & 0,42 & 1,00 & 0,81 & $-0,64$ & $-0,19$ & $-0,23$ & 0,36 & 1,00 & 0,83 & $-0,47$ \\
\hline News - picture & 0,01 & 0,09 & 0,15 & 0,20 & 0,02 & $-0,27$ & 0,01 & $-0,01$ & 0,21 & 0,41 & 0,03 & $-0,43$ \\
\hline News - annotation & 0,11 & 0,23 & 0,18 & 0,07 & 0,08 & $-0,19$ & 0,11 & 0,23 & 0,29 & 0,18 & 0,11 & $-0,20$ \\
\hline Sitemap & $-0,15$ & 0,31 & 0,07 & 0,41 & 0,58 & $-0,06$ & $-0,09$ & 0,13 & 0,06 & 0,40 & 0,67 & $-0,01$ \\
\hline Picture & $-0,18$ & 0,33 & $-0,09$ & 0,10 & 0,17 & 0,10 & $-0,25$ & 0,33 & $-0,16$ & $-0,18$ & 0,20 & 0,27 \\
\hline Video & $-0,13$ & 0,14 & 0,18 & 0,03 & $-0,01$ & $-0,03$ & $-0,04$ & 0,11 & 0,28 & 0,22 & 0,12 & $-0,14$ \\
\hline Map & 0,68 & 0,11 & $-0,37$ & $-0,11$ & $-0,17$ & $-0,05$ & 0,66 & 0,41 & $-0,02$ & $-0,15$ & $-0,15$ & $-0,18$ \\
\hline h1 & 0,66 & 0,44 & $-0,75$ & 0,54 & 0,33 & $-0,28$ & 0,41 & 0,52 & $-0,61$ & 0,14 & 0,27 & $-0,30$ \\
\hline h2 & 0,79 & 0,29 & $-0,39$ & 0,46 & 0,20 & $-0,42$ & 0,67 & 0,39 & $-0,03$ & 0,22 & 0,14 & $-0,48$ \\
\hline h3 & 0,08 & 0,44 & 0,18 & $-0,06$ & 0,08 & $-0,03$ & 0,04 & 0,58 & 0,33 & $-0,24$ & 0,14 & 0,20 \\
\hline Slogan & 0,40 & $-0,06$ & $-0,51$ & 0,65 & 0,87 & $-0,04$ & 0,42 & $-0,23$ & $-0,53$ & 0,45 & 0,82 & $-0,05$ \\
\hline Symbols - general & $-0,12$ & 0,55 & 0,09 & 0,54 & 0,31 & $-0,32$ & $-0,17$ & 0,38 & 0,17 & 0,59 & 0,51 & $-0,33$ \\
\hline Symbols - cult. & $-0,62$ & 0,24 & 0,31 & 0,85 & 0,74 & $-0,30$ & $-0,57$ & $-0,31$ & 0,05 & 1,00 & 0,86 & $-0,31$ \\
\hline
\end{tabular}

Tab. 7. Comparison of values received from the calculation with consideration of primary $(P)$, secondary (S) and tertiary $(T)$ cultural dimension with values given by the calculation without the impact of $P, S$ and $T$ cultural dimensions. Both methods have very similar results. Values related to

Hofstede's cultural dimensions are: Power distance (PD), Individualism vs collectivism (IND), Masculinity vs femininity (MAS), Uncertainty avoidance (UA), Long term orientation (LTO), Indulgence vs restraint (IVR). Source: Author. 
Table 7 clearly shows that both methods offer very similar values, which confirms the correctness of the procedure. However, we can notice some differences due to the fact that the occurrence of a given element can be influenced by several cultural dimensions. This means mainly that the one cultural dimension could lead to the presence of an element, but another one could lead to the suppression of the same element. To make general conclusions, values from method one will therefore be used. This method takes into account the extreme values of cultural dimensions for the country, which should, at least to some extent, shield any interaction with other elements of cultural dimensions. ${ }^{10}$

\subsection{Culturally sensitive web elements}

From the previous tables, it can be seen that due to the similar values of cultural dimensions from examined states certain elements prove to be significant for more cultural dimensions. This is logical, because if two countries are close in more cultural dimensions and we compare these with a country that has different values in given cultural dimensions, the same elements may be in the comparison evaluated as significant for more cultural dimensions. In this case, it is necessary to take into account the difference in the value of the presence of the element. It is also necessary to take into account the values of cultural dimensions in the countries where such cultural dimension was marked as primary or secondary.

Taking into account what has been mentioned above, we can derive the following linking of website elements and cultural dimensions. Table 8 shows all significant elements depending on each cultural dimension. These are any elements that reached significant difference values. It can be seen that in many cases there are elements that are linked to more cultural dimensions. This is not necessarily wrong. We can see it as reflecting that the presence of the element on a website in a state with a certain extreme value of cultural dimension should have a positive effect on user acceptance and ease of use.

\begin{tabular}{|c|c|c|c|c|c|c|c|c|c|}
\hline IND & $\mathrm{H} 2$ & Map & Form & Slogan & $\mathrm{H} 1$ & & & & \\
\hline COL & $\begin{array}{l}\text { Symbols - } \\
\text { cult. }\end{array}$ & & & & & & & & \\
\hline $\mathbf{U A}(\mathbf{H})$ & $\mathrm{H} 3$ & H1 & $\begin{array}{c}\text { Banner - } \\
\text { small }\end{array}$ & Map & $\begin{array}{c}\text { Symbols - } \\
\text { general }\end{array}$ & $\mathrm{H} 2$ & & & \\
\hline $\mathbf{U A}(\mathbf{L})$ & $\begin{array}{l}\text { Banner - } \\
\text { animated }\end{array}$ & & & & & & & & \\
\hline $\mathbf{P D}(\mathrm{H})$ & Search & & & & & & & & \\
\hline $\mathbf{P D}(\mathbf{L})$ & E-mail & H1 & Address & Phone & Slogan & $\begin{array}{c}\text { Pictorial } \\
\text { nav. }\end{array}$ & & & \\
\hline LTO(H) & $\begin{array}{c}\text { Symbols - } \\
\text { cult. }\end{array}$ & $\begin{array}{l}\text { News - } \\
\text { headline }\end{array}$ & $\begin{array}{c}\text { Symbols - } \\
\text { general }\end{array}$ & Slogan & $\begin{array}{l}\text { News - } \\
\text { picture }\end{array}$ & Sitemap & & & \\
\hline LTO(L) & Newsletter & & & & & & & & \\
\hline $\operatorname{MAS}(\mathbf{H})$ & Links section & $\begin{array}{c}\text { Symbols - } \\
\text { cult. }\end{array}$ & $\begin{array}{c}\text { News - } \\
\text { headline }\end{array}$ & Slogan & $\begin{array}{c}\text { Banner - } \\
\text { small }\end{array}$ & Sitemap & $\begin{array}{c}\text { Iconic } \\
\text { nav. }\end{array}$ & $\begin{array}{c}\text { Symbols - } \\
\text { general }\end{array}$ & Form \\
\hline $\operatorname{MAS}(\mathrm{L})$ & E-mail & $\begin{array}{l}\text { Banner - } \\
\text { full-width }\end{array}$ & & & & & & & \\
\hline $\operatorname{IVR}(\mathbf{H})$ & $\begin{array}{l}\text { Banner- } \\
\text { animated }\end{array}$ & Newsletter & & & & & & & \\
\hline $\operatorname{IVR}(\mathrm{L})$ & $\mathrm{H} 2$ & $\begin{array}{c}\text { News - } \\
\text { headline }\end{array}$ & $\begin{array}{l}\text { News - } \\
\text { picture }\end{array}$ & $\begin{array}{c}\text { Banner - } \\
\text { static }\end{array}$ & & & & & \\
\hline
\end{tabular}

Tab. 8. Website elements depending on cultural dimensions: Power distance (PD), Individualism vs collectivism (IND vs COL), Masculinity vs femininity (MAS), Uncertainty avoidance (UA), Long term orientation (LTO), Indulgence vs restraint (IVR). $H$ means high value. $L$ means low value. Each row

\footnotetext{
${ }^{10}$ To eliminate the interactions of cultural dimensions, i.e. the influence of different cultural dimensions on element depiction is not completely possible. It is because of the complexity of the culture. This method should eliminate this fact as much as possible.
} 
contains culturally sensitive elements related to the cultural dimension from the first column. Source: Author.

If we go a little bit deeper, we should try to take into account the mutual influence of cultural dimensions, i.e. especially taking into account the aforementioned selected primary and possibly secondary dimensions. This gives us Table 9.

\begin{tabular}{|c|c|c|c|c|c|c|c|}
\hline IND & $\begin{array}{l}\text { Headlines } \\
(\mathrm{H} 1, \mathrm{H} 2)\end{array}$ & Map & Form & Slogan & & & \\
\hline COL & $\begin{array}{l}\text { Symbols - } \\
\text { cult. }\end{array}$ & & & & & & \\
\hline $\mathbf{U A}(\mathbf{H})$ & $\begin{array}{c}\text { Headlines } \\
(\mathrm{H} 1, \mathrm{H} 2, \mathrm{H} 3)\end{array}$ & $\begin{array}{c}\text { Symbols - } \\
\text { general }\end{array}$ & & & & & \\
\hline $\mathbf{U A}(\mathbf{L})$ & $\begin{array}{l}\text { Banner- } \\
\text { animated }\end{array}$ & & & & & & \\
\hline $\mathbf{P D}(\mathrm{H})$ & Search & & & & & & \\
\hline PD(L) & E-mail & $\mathrm{H} 1$ & Address & Phone & Iconic nav. & & \\
\hline LTO(H) & $\begin{array}{l}\text { Symbols - } \\
\text { cult. }\end{array}$ & $\begin{array}{l}\text { Symbols - } \\
\text { general }\end{array}$ & $\begin{array}{c}\text { News - } \\
\text { headline + } \\
\text { picture }\end{array}$ & & & & \\
\hline LTO(L) & Newsletter & & & & & & \\
\hline $\operatorname{MAS}(\mathbf{H})$ & Links section & $\begin{array}{l}\text { Symbols - } \\
\text { cult. }\end{array}$ & $\begin{array}{c}\text { Banner- } \\
\text { small }\end{array}$ & Slogan & Sitemap & $\begin{array}{c}\text { News - } \\
\text { headline }\end{array}$ & Iconic nav. \\
\hline $\operatorname{MAS}(\mathbf{L})$ & $\begin{array}{l}\text { Banner - full- } \\
\text { width }\end{array}$ & & & & & & \\
\hline $\operatorname{IVR}(\mathrm{H})$ & Newsletter & & & & & & \\
\hline $\operatorname{IVR}(\mathbf{L})$ & $\mathrm{H} 2$ & $\begin{array}{c}\text { News - } \\
\text { headline }+ \\
\text { picture }\end{array}$ & $\begin{array}{c}\text { Banner - } \\
\text { static }\end{array}$ & & & & \\
\hline
\end{tabular}

Tab. 9. Adjusted list of website elements depending on cultural dimensions: Power distance (PD), Individualism vs collectivism (IND vs COL), Masculinity vs femininity (MAS), Uncertainty avoidance (UA), Long term orientation (LTO), Indulgence vs restraint (IVR). The mutual influence of primary cultural dimensions is taken into account. $H$ means high value. $L$ means low value. Each row contains culturally sensitive elements related to cultural dimension from the first column. Source: Author

Table 9 can give us recommendations on what elements should we choose if we want to create a website for a country with the corresponding cultural dimensions. The fact that some elements are repeated (even when taking into account the primary dimension) in several cultural dimensions is not incorrect. The influence of more cultural dimensions on one website feature can also be traced in literature and it is the result of the aforementioned interaction of dimensions. For example, symbols and pictures of national identity are, according to (Singh et al., 2005b), a reflection of collectivism. According to (Reinecke \& Bernstein, 2011), photos closely connected with the country reflect low levels of power distance. The use of support for websites is attributed to a high value of power distance according to (Reinecke \& Bernstein, 2011) and to a high value of the uncertainty avoidance according to (Sachau \& Hutchinson, 2012) or (Singh et al., 2005b). An emphasis on the quality and prestige of a company in the form of awards or rankings shown on the website is attributed to a high value power distance, according to (Singh et al., 2005b; Calabrese et al., 2014), and to a high value of masculinity, according to (Karaçay-Aydin et al., 2010), or low value of context according to (Singh et al., 2005b).

\subsection{Culturally sensitive website features}

For a comprehensive analysis of the general characteristics of websites, the results shown in Table 5 will be compared with the characteristics arising from the literature. 
Based on the findings from several studies that focused on research about the relation of website features and culture, the following characteristics were determined for each country. Those characteristics were selected that were relevant to the characteristics observed in this study. The following studies were used: (Reinecke \& Bernstein, 2011; Singh et al., 2005b; Calabrese et al., 2014; Karaçay-Aydin et al., 2010; Sachau \& Hutchinson, 2012).

\section{The Czech Republic}

- High uncertainty avoidance: organized information hierarchy, linear navigation paths, showing the position of the user, sitemap, search, clear navigation and preventing errors, use of colour, web visitor support

- High long-term orientation: most information at interface level, content can be arranged around a focal area

\section{US}

- High individualism: use of colour to encode information, high text-to-image ratio, low multimodality, monotonously coloured interface, personalization

- Low long-term orientation: reduced information density, content highly structured into small units

\section{China}

- High long-term orientation: most information at interface level, content can be arranged around a focal area

- High power distance: linear navigation, few links, minimized navigation possibilities, structured data, little information at first level, providing strong support with the help of wizards

- High collectivism: traditional colours and images, high image-to-text ratio, high multimodality, colourful interface, newsletter, symbols and pictures of national identity

- Low uncertainty avoidance: most information at interface level, complex interfaces, nonlinear navigation, variety of choices

\section{Chile}

- High uncertainty avoidance: organized information hierarchy, linear navigation paths, showing the position of the user, sitemap, search, clear navigation and preventing errors, use of colour, web visitor support

- High collectivism: traditional colours and images, high image-to-text ratio, high multimodality, colourful interface, newsletter, symbols and pictures of national identity

- Low masculinity: little saturation, pastel colours, allowing exploration and different paths to navigate, multiple choices

\section{Saudi Arabia}

- High power distance: linear navigation, few links, minimized navigation possibilities, structured data, little information at first level, providing strong support with the help of wizards 
- High uncertainty avoidance: organized information hierarchy, linear navigation paths, showing the position of the user, sitemap, search, clear navigation and preventing errors, use of colour, web visitor support

- High collectivism: traditional colours and images, high image-to-text ratio, high multimodality, colourful interface, newsletter, symbols and pictures of national identity

\section{Japan}

- High masculinity: highly contrasting, bright colours, restricted navigation possibilities, limited choices

- High uncertainty avoidance: organized information hierarchy, linear navigation paths, showing the position of the user, sitemap, search, clear navigation and preventing errors, use of colour, web visitor support

- High long-term orientation: most information at interface level, content can be arranged around a focal area

\section{Nigeria}

- Low long-term orientation: reduced information density, content highly structured into small units

- High power distance: linear navigation, few links, minimized navigation possibilities, structured data, little information at first level, providing strong support with the help of wizards

- High collectivism: traditional colours and images, high image-to-text ratio, high multimodality, colourful interface, newsletter, symbols and pictures of national identity

\section{Latvia}

- Low masculinity: little saturation, pastel colours, allowing exploration and different paths to navigate, multiple choices

- High individualism: use of colour to encode information, high text-to-image ratio, low multimodality, monotonously coloured interface, personalization

\section{Austria}

- Low power distance: different access and navigation possibilities, nonlinear navigation, data does not have to be structured, most information at interface level, hierarchy of information less deep, support is only rarely needed

- High masculinity: highly contrasting, bright colours, restricted navigation possibilities, limited choices

- High uncertainty avoidance: organized information hierarchy, linear navigation paths, showing the position of the user, sitemap, search, clear navigation and preventing errors, use of colour, web visitor support

If we summarize these findings, we should expect in the Czech Republic a simple structure slightly in contrast with content arranged around a central area, the use of colour and high information density. In the United States, we should expect the use of colour to encode the information, high text-to-image ratio, low colour, low information density and structured web, 
i.e. low complexity. For China, the theory implies a high proportion of images and high use of colours. Information density and overall complexity could be either small or high. Here is the theory not consistent, it would be probably dependent on the influence of the dominant cultural dimension. According to the theory, Chile should be characterized by a simple structure, high ratio of images, the use of colours and, in contrast, small saturation, the use of pastel colours and greater complexity. Sites in Saudi Arabia should show simplicity, low information density, the use of colours and a high proportion of graphics. Japanese sites should exhibit a high use of colours and saturation, simple and sophisticated navigation and clear structure in contrast with the content arranged around a focal area and a higher information density. Sites in Nigeria should have a low information density, should be simple, coloured with a higher level of graphics. Latvian sites should have low colour and saturation, a more complex structure, a small proportion of graphics and colour usage for information encoding. Finally, websites from Austria should be characterized by a high information density and colour saturation. Information regarding the complexity is inconsistent (from high uncertainty avoidance can be derived small complexity and from low power distance can be derived high complexity).

If we compare the measured data with the theory, we can find consensus in most cases. Let us take a closer look at the ambiguous values. In the Czech Republic, the complexity of the site appears to be problematic, as it should be simple according to the theory, but slightly higher values are shown. This is no doubt influenced by contrasting layout options for website content that can make sites more complex. Higher saturation for sites from the United States can be attributed to the use of colour to encode information. This results in the use of contrast and highly saturated colours for important elements. The most difficult situation is in the case of China. It is an example of a country that has cultural dimensions that influence websites in a way that does not match. According to the high long-term orientation, Chinese sites should be very complex with a large amount of information. In contrast, according to high power distance, websites should contain little information and a clear and simple structure. Slightly simplified, it is the contrast between simplicity and complexity. The frequency (information density: 22x1, 16x2, 0x3, 3x4 and 9x5; complexity: 22x1, 12x2, 4x3, 7x4 and 5x5) shows that in China, mostly simpler sites are crated with a low information density. But on the other hand, there are also more complex sites with a higher information density.

In Chile, the contrast is mainly in properties derived from low masculinity. However, this dimension has, in comparison with two more dominant dimensions, certainly less influence. Another variable may also be a temperament typical for South America, which refers to the colours and directness. In Saudi Arabia, the contrast is in the use of colours, which should be higher. Mainly pastel colours are used there, i.e. brown, ochre, yellow, orange, combined with a blue or green. However, these are colours that are traditional within the given culture. We are thus observing a predominant influence of traditions. Japanese websites are the most complicated. This country has three extreme cultural dimensions. Japanese sites thus show at a first glance many serious contradictions. Japanese websites should be simpler with clear navigation and at the same time should have a complex structure with much information presented. Japanese websites are created in the way described. There are simple sites on the one side, but on the other side, there are more often complex and information-rich sites. In such cases, these sites are usually completed by sitemaps or well-structured graphical navigation.

For Nigeria, what might be seen as problematic is the not very high value of graphics-to-text ratio. This may be due to the overall higher level of simplicity, or straightforwardness, of Nigerian sites. The problem with the values of the Latvian sites can be seen in particular in 
the complexity which should be higher but is in fact very low. The reason for this contradiction can be found in the low context of this culture ${ }^{11}$. Low context, according to the theory, points to a simple structure and clear communication of information. In Austria, there is a slight conflict in the value of colour, which should be higher. Colours on these websites are used primarily for highlighting important elements, which corresponds with a higher value of saturation. Complex structure is then "overridden" by simplicity, which is based on the other two dimensions. The analysis implies that the data are in harmony, despite the minor nuances discussed above.

The final findings concern the common elements observed across the websites from analysed countries. Website development, just like any other craft, has its own principles that are fixed, regardless of where the website was created. Therefore, the average website presents many common characteristics that can be described as the building blocks. If we are to determine the format of an average culture-independent site, such a website should include in the header a company's logo and menu, in the body a slider (which will be interactive with high probability), images, title, news, symbols to simplify the communication of selected information, and in the footer will very probably be contact information (phone, e-mail address) and block links.

From the results it is evident that there are web elements and features that are the so-called essential part of websites, but also elements that are influenced by culture. These findings give us also an answer to our research question: "Are there any differences in web design approach and used website elements between the selected countries?" The results clearly support the answer that websites are culturally sensitive and that used website elements differ according to the country of origin.

This case study based on the content analysis of websites from several countries has provided new insights regarding the linking of web elements and characteristics with culture (characterized by Hofstede's cultural dimensions). A comparison with theory suggests that it is definitely not a comprehensive and exhaustive list. Culture is very complex and this multidisciplinary filed is still very little explored, thus additional detailed researches are required. Some elements are in fact reflected in more cultural dimensions and, vice versa, one country may have, due to the specific values of cultural dimensions, conflicting recommendations. It is therefore important to focus mainly on these issues and determine whether it is a result of various important influences within the culture, whether it is the interaction of dominant cultural dimensions, or whether it was just a misleading finding within the results or theory.

\section{Acknowledgement}

The paper was processed with support from internal grant F4/1/2019 at the Faculty of Informatics and Statistics, Prague University of Economics and Business.

\section{ORCID}

Radim Cermak (D) http://orcid.org/0000-0002-6886-7642

\footnotetext{
${ }^{11}$ Low versus high context is one of Hall's cultural dimensions representing a different categorization of culture.
} 


\section{References}

Adam, S., Featherstone, M., \& Day, K. W. H. (2014). A comparison of the marketing capabilities of SME websites in Australian and U.S. domains. Journal of Technology Research, 5, 1-20.

Ahmed, T., Mouratidis, H., \& Preston, D. (2009). Website design guidelines: High power distance and highcontext culture. International Journal of Cyber Society and Education, 2(1), 47-60.

Ailon, G. (2008). Mirror, Mirror on the Wall: Culture's Consequences in A Value Test of its Own Design. Academy of Management Review, 33(4), 885-904. https://doi.org/10.5465/amr.2008.34421995

Albers-Miller, N. D., \& Gelb, B. D. (1996). Business Advertising Appeals as a Mirror of Cultural Dimensions: A Study of Eleven Countries. Journal of Advertising, 25(4), 57-70. https://doi.org/10.1080/00913367.1996.10673512

Calabrese, A., Capece, G., Di Pillo, F., \& Martino, F. (2014). Cultural adaptation of web design services as critical success factor for business excellence. Cross Cultural Management: An International Journal, 21(2), 172-190. https://doi.org/10.1108/ccm-09-2012-0070

Cermak, R. (2017). Metodika pro lokalizaci webových stránek z pohledu webdesignu. Dissertation thesis. University of Economics, Prague.

Chavanne, D. (2007) Neuroscience and Culture. http://neuroeconomics.typepad.com/neuroeconomics/2007/01/neuroscience an.html

Cyr, D. (2008). Modeling Web Site Design Across Cultures: Relationships to Trust, Satisfaction, and E-Loyalty. Journal of Management Information Systems, 24(4), 47-72. https://doi.org/10.2753/mis0742-1222240402

Cyr, D., \& Trevor-Smith, H. (2004). Localization of Web design: An empirical comparison of German, Japanese, and United States Web site characteristics. Journal of the American Society for Information Science and Technology, 55(13), 1199-1208. https://doi.org/10.1002/asi.20075

Daryanto, A., Khan, H., Matlay, H., \& Chakrabarti, R. (2013). Adoption of country-specific business websites. Journal of Small Business and Enterprise Development, 20(3), 650-660. https://doi.org/10.1108/jsbed-04$\underline{2013-0048}$

Delude, C. M. (2008). Culture influences brain function, study shows. MIT TechTalk, 52(14), 4.

Hashim, N. H., Hasan, H., \& Sinnapan, S. (2007). Australian Online Newspapers: A Website content analysis approach to measure interactivity. In ACIS 2007 Proceedings (56). https://aisel.aisnet.org/acis2007/56

Hofstede, G. (2002). Dimensions do not exist: A reply to Brendan McSweeney. Human Relations, 55(11), 13551361. https://doi.org/10.1177/00187267025511004

Hofstede, G. (2015, December 8). Dimension data matrix. http://geerthofstede.nl/

Karacay-Aydin, G., Akben-Selcuk, E., \& Aydin-Altinoklar, A. E. (2009). Cultural Variability in Web Content: A Comparative Analysis of American and Turkish Websites. International Business Research, 3(1), 97-103. https://doi.org/10.5539/ibr.v3n1p97

Kirkman, B. L., Lowe, K. B., \& Gibson, C. B. (2006). A quarter century of Culture's Consequences: a review of empirical research incorporating Hofstede's cultural values framework. Journal of International Business Studies, 37(3), 285-320. https://doi.org/10.1057/palgrave.jibs.8400202

Li, X., Hess, T. J., McNab, A. L., \& Yu, Y. (2009). Culture and acceptance of global web sites. ACM SIGMIS Database: The DATABASE for Advances in Information Systems, 40(4), 49-74. https://doi.org/10.1145/1644953.1644959

Marcus, A. (2003). Are you cultured?. New Architect, 8(3), 28-31.

Marcus, A., \& Gould, E. W. (2000). Crosscurrents: cultural dimensions and global Web user-interface design. Interactions, 7(4), 32-46. https://doi.org/10.1145/345190.345238

McSweeney, B. (2002a). Hofstede's Model of National Cultural Differences and their Consequences: A Triumph of Faith - a Failure of Analysis. Human Relations, 55(1), 89-118. https://doi.org/10.1177/0018726702551004

McSweeney, B. (2002b). The essentials of scholarship: A reply to Geert Hofstede. Human Relations, 55(11), 1363-1372. https://doi.org/10.1177/00187267025511005

Milner, L. M., \& Collins, J. M. (2000). Sex-Role Portrayals and the Gender of Nations. Journal of Advertising, 29(1), 67-79. https://doi.org/10.1080/00913367.2000.10673604

Nordhoff, M., August, T., Oliveira, N. A., \& Reinecke, K. (2018). A Case for Design Localization: Diversity of Website Aesthetics in 44 Countries. In Proceedings of the $2018 \mathrm{CHI}$ Conference on Human Factors in 
Computing Systems (Paper 337, pp. 1-12). Association for Computing Machinery. https://doi.org/10.1145/3173574.3173911

Pratap S., \& Kumar J. (2019). A Dimensional Analysis Across India to Study How National Cultural Diversity Affects Website Designs. In: Chakrabarti A. (ed.) Research into Design for a Connected World. Smart Innovation, Systems and Technologies (pp. 653-664). Springer. https://doi.org/10.1007/978-981-13-5977$\underline{455}$

Průcha, J. (2007). Interkulturní psychologie. Portál.

Radziszewska, A. (2019). Cultural Determinants of E-commerce Website Quality Assessment. In Proceedings of the 42nd International Scientific Conference on Economic and Social Development (pp. 17-25). Varazdin Development and Entrepreneurship Agency.

Reinecke, K., \& Bernstein, A. (2011). Improving performance, perceived usability, and aesthetics with culturally adaptive user interfaces. ACM Transactions on Computer-Human Interaction, 18(2), 1-29. https://doi.org/10.1145/1970378.1970382

Reinecke, K., \& Bernstein, A. (2013). Knowing What A User Likes: A Design Science Approach To Interfaces That Automatically Adapt To Culture. MIS Quarterly, 37(2), 427-453.

Sachau, L. L., \& Hutchinson, S. R. (2012). Trends in culturally relevant interface design features for Latino Web site users. Educational Technology Research and Development, 60(6), 1033-1050. https://doi.org/10.1007/s11423-012-9270-5

Shneor, R. (2012). Influences of Culture, Geography and Infrastructure on Website Localization Decisions. Cross Cultural Management, 19(3), 352-374.

Imm Ng, S., Anne Lee, J., \& Soutar, G. N. (2007). Are Hofstede's and Schwartz's value frameworks congruent? International Marketing Review, 24(2), 164-180. https://doi.org/10.1108/02651330710741802

Simon, S. J. (2001). The impact of culture and gender on web sites. ACM SIGMIS Database, 32(1), 18-37. https://doi.org/10.1145/506740.506744

Singh, N., \& Matsuo, H. (2002). Measuring cultural adaptation on the web: a study of US and Japanese web sites. In Advances in Consumer Research (pp. 271-272). Association for Consumer Research.

Singh, N. (2003). Culture and the world wide web: A cross-cultural analysis of web sites from France, Germany and USA. In AMA Winter Educators'Conference Proceedings (vol. 14). American Marketing Association.

Singh, N., Zhao, H., \& Hu, X. (2003). Cultural Adaptation on the Web. Journal of Global Information Management, 11(3), 63-80. https://doi.org/10.4018/igim.2003070104

Singh, N., \& Baack, D. W. (2006). Web Site Adaptation: A Cross-Cultural Comparison of U.S. and Mexican Web Sites. Journal of Computer-Mediated Communication, 9(4), 71-86. https://doi.org/10.1111/j.10836101.2004.tb00298.x

Singh, N., Kumar, V., \& Baack, D. (2005a). Adaptation of cultural content: evidence from B2C e-commerce firms. European Journal of Marketing, 39(1/2), 71-86. https://doi.org/10.1108/03090560510572025

Singh, N., Zhao, H., \& Hu, X. (2005b). Analyzing the cultural content of web sites. International Marketing Review, 22(2), 129-146. https://doi.org/10.1108/02651330510593241

Singh, N., Park, J. E., \& Kalliny, M. (2012). A framework to localize international business to business web sites. ACM SIGMIS Database, 44(1), 56. https://doi.org/10.1145/2436239.2436243

Steenkamp, J. E. M. (2001). The role of national culture in international marketing research. International Marketing Review, 18(1), 30-44. https://doi.org/10.1108/02651330110381970

Tang, L., \& Koveos, P. E. (2008). A framework to update Hofstede's cultural value indices: economic dynamics and institutional stability. Journal of International Business Studies, 39(6), 1045-1063. https://doi.org/10.1057/palgrave.jibs.8400399

Vyncke, F., \& Bergman, M. (2010). Are culturally congruent websites more effective? An overview of a decade of empirical evidence. Journal of Electronic Commerce Research, 11(1), 14-29.

Wurtz, E. (2005). Intercultural Communication on Web sites: A Cross-Cultural Analysis of Web sites from HighContext Cultures and Low-Context Cultures. Journal of Computer-Mediated Communication, 11(1), 274299. https://doi.org/10.1111/j.1083-6101.2006.tb00313.x

Yalcin, S., Singh, N., Dwivedi, Y. K., Apil, A. R., \& Sayfullin, S. (2011). Culture and localization on the web: Evidence from multinationals in Russia and Turkey. Journal of Electronic Commerce Research, 12(1), 94114.

Yin, R. K. (2014). Case Study Research Design and Methods. Sage. 
Zandpour, F., Campos, V., Catalano, J., Chang, C., Cho, Y. D., Hoobyar, R., Jiang, S., Lin, M., Madrid, S., Scheideler, H., \& Osborn, S. T. (1994). Global Reach and Local Touch: Achieving Cultural Fitness in TV Advertising. Journal of Advertising Research, 34(5), 35-63.

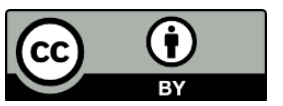

Copyright (c) 2020 by the author(s). Licensee Prague University of Economics and Business, Czech Republic. This article is an open access article distributed under the terms and conditions of the Creative Commons Attribution License (CC BY), which permits use, distribution and reproduction in any medium, provided the original publication is properly cited, see http://creativecommons.org/licenses/by/4.0/. No use, distribution or reproduction is permitted which does not comply with these terms.

The article has been peer-reviewed.

Editorial record: First submission received on 29 May 2020. Revisions received on 30 August 2020 and 17 September 2020. Accepted for publication on 21 September 2020. The editor in charge coordinating the peerreview of this manuscript and approving it for publication was Stanislava Mildeova (D. 